\title{
CONSIDERAÇÕES DO PANORAMA PRODUTIVO DA AQUICULTURA NO BRASIL
}

\author{
Julianne Almeida Rodrigues ${ }^{1}$ \\ Fernanda Dassie Rangel ${ }^{2}$ \\ Winny Silva Trugilho ${ }^{3}$ \\ Bruno Fardim Christo 4 \\ Elaine Cristina Gomes da Silva ${ }^{5}$
}

Resumo: A aquicultura vem sendo praticada e estimulada por diversas regiões do Brasil sob a ótica do desenvolvimento social e da diversificação da economia rural, em conjunto com a preservação ambiental. Pode ser utilizada como ferramenta de melhoria das condições de vida do produtor rural e das comunidades costeiras formadas por pescadores artesanais. Por meio de pesquisas de caráter exploratório e descritivos, foi feita uma caracterização qualitativa referente a aquicultura. O presente trabalho teve como objetivo coletar informações referentes ao panorama da aquicultura nacional em órgãos públicos competentes. Pôde-se perceber que o Brasil possui um grande potencial para o desenvolvimento da aquicultura, e que ela é uma prática vantajosa. De modo geral, constatou-se que a aquicultura tem crescido de forma expressiva no Brasil nos últimos anos.

Palavras-chave: Aquicultura; Crescimento econômico; Expansão produtiva.

\footnotetext{
${ }^{1}$ Zootecnia/UFES, Brasil. E-mail: julianne_ar@hotmail.com.

2 E-mail: Engenharia Química/UFES, Brasil. E-mail: fernanda.dassierangel@gmail.com.

${ }^{3}$ Zootecnia/UFES, Brasil. E-mail: winnytrugilho@hotmail.com.

${ }^{4}$ Engenharia Florestal/UFES, Brasil. E-mail: twilight.mancini@hotmail.com.

${ }^{5}$ Administração/UNESC, Brasil. E-mail: ecristinags@gmail.com.
} 